\title{
ENTRE EL DISCURSO OFICIAL Y LA REALIDAD: LA POLÍTICA EXTERIOR DE MÉXICO HACIA ÁFRICA, 2012-2018
}

\author{
BETWEEN OFFICIAL DISCOURSE AND REALITY: \\ MEXICO'S FOREIGN POLICY TOWARDS AFRICA, \\ 2012-2018
}
ENTRE LE DISCOURS OFFICIEL ET LA RÉALITÉ: LA POLITIQUE DU MEXIQUE À L'ÉGARD DE L'AFRIQUE (2012-2018)

\author{
Hilda Varela Barraza \\ El Colegio de México \\ hvarela@colmex.mx
}

\begin{abstract}
Resumen: Estudiar la política exterior de México hacia África no es tarea fácil: a las dificultades para obtener información cualitativa se suma la notable ausencia de ese continente en la agenda de política exterior y en la opinión pública. Entre desconocimiento, desinterés y prejuicios racistas, se aprecia en esencia la continuidad de la política exterior hacia África. En los primeros años del periodo estudiado (2012-2018), aquel continente aparecía como un título más en documentos oficiales, sin contenido. En los últimos años del sexenio se desplegó un relativo activismo de la política exterior económica, en lo que parecería un intento de seguir un comportamiento similar al de otras economías emergentes (China, India, Turquía), pero con capacidades limitadas.

Palabras clave: discurso oficial; África; transformaciones mundiales;

Enrique Peña Nieto; primarización de la economía; política exterior;

México.
\end{abstract}

AвSTRACT: Studying Mexico's foreign policy towards Africa is not an easy task. The difficulties of obtaining qualitative information are compounded by the notable absence of that continent from the foreign policy agenda and in public opinion. Between ignorance, disinterest, and racist prejudices, the essential feature of foreign policy towards Africa is one of continuity. In the first years of the period studied (2012-2018), that continent appeared as just an- 
other title in official Mexican documents, with little content. In the latter years of the administration a relatively greater activism in foreign economic policy was deployed, in what would seem to be an attempt to emulate the behavior of other emerging economies, such as China, India, and Turkey, but with limited capabilities.

Keywords: official discourse; Africa; world transformations; Enrique

Peña Nieto; primarization of the economy; foreign policy; Mexico.

\section{Traducción de Gonzalo Celorio Morayta}

Résumé: Il n'est pas simple d'étudier la politique du Mexique vis-à-vis de l'Afrique. Aux difficultés pour obtenir de l'information fiable s'ajoute le fait que ce continent-là ne figure pas vraiment dans l'agenda de la politique étrangère mexicaine ni dans celui de l'opinion publique. Sous la méconnaissance, le désintérêt et les préjugés racistes, on arrive à percevoir la continuité d'une vague politique mexicaine envers l'Afrique. Le long des premières années du gouvernement qui nous intéresse, le continent en question était cité dans des documents officiels mexicains qui en parlaient à peine. Par contre, vers la fin de cette période présidentielle la politique économique extérieure du Mexique a été animée par un certain activisme, suivant l'exemple d'autres puissances émergentes (telles que la Chine, l'Inde ou encore la Turquie), mais ses ressources étaient limitées.

Mots clefs: Discours officiel; Afrique; transformations mondiales; Enrique Peña Nieto; primarisation de l'économie; politique étrangère; Mexique.

\section{Traducción de Bernardo Mabire}

Fecha de recepción: diciembre de 2018

Fecha de aceptación: febrero de 2019 
$\mathrm{E}$ L continente africano sigue siendo desconocido en México. A esto se suma la carga negativa del imaginario occidental, dominado por prejuicios milenarios, en especial en torno a los pueblos de piel negra, además del desinterés por África, tanto entre los funcionarios que toman decisiones de política exterior como entre la población y los líderes mexicanos (opinión pública para los fines de este artículo).

África nunca ha sido una región prioritaria en la agenda de política exterior de México (PEM). En gobiernos que precedieron al de Enrique Peña Nieto (EPN) pueden apreciarse aspectos que han caracterizado la esencia de la política exterior de México hacia África (PEMAf), en especial en cuanto a la ausencia de una definición política, que es la base para identificar los objetivos políticos y económicos de México a largo plazo y para elaborar estrategias coherentes, realizar acciones concretas y evaluar sus resultados.

En ese sexenio, el desinterés por África contrastaba con el eje central establecido en el Plan Nacional de Desarrollo (PND) 2013-2018, cuyo objetivo era forjar un México incluyente, solidario y con responsabilidad internacional. En la marca México ${ }^{1}$ se proyectaba un país estable, una economía abierta y un gobierno comprometido con reformas económicas estructurales para atraer inversiones extranjeras directas (IED). En documentos de la Secretaría de Relaciones Exteriores (SRE), las referencias a África eran expresiones de solidaridad, ante triunfos electorales o en favor de la paz. Las menciones a su importancia en la economía mundial subrayaban sus riquezas naturales, como si fuese un continente despoblado.

En los últimos años del sexenio -con la política proteccionista de la administración Trump en Estados Unidos (EEUU)se registró un cambio, con un relativo activismo económico en comparación con administraciones pasadas, pero muy

${ }^{1}$ Secretaría de Comunicaciones y Transportes, "La marca México está hecha de logros", México, sct, 13 de noviembre de 2018, https://www. gob.mx/sct/articulos/la-marca-mexico-esta-hecha-de-logro 
débil en relación con otras regiones, difundido por medios vinculados con sectores empresariales, que "descubrían" que África era el continente del futuro. En esa perspectiva destacaban los países africanos como posibles y prometedores mercados para inversiones y productos mexicanos.

Los argumentos son los siguientes. Se plantean las transformaciones mundiales como un desafío tanto para México como para África, con una redefinición, no exenta de contradicciones, de la PEM y la PEMAf. Se identifica el surgimiento de una "estructura hibrida del poder internacional", 2 en cuyo contexto han surgido potencias medias emergentes (como México). Se observa la tendencia a privilegiar la economía, con la fragmentación del proceso de toma de decisiones y, en parte, como un intento para aminorar el impacto de la dinámica de "crecimiento-hundimiento", ${ }^{3}$ se exportaban productos primarios a países africanos.

Con base en la trayectoria de la PEMAf, de carácter reactivo, errática y coyuntural, surgen las siguientes preguntas de investigación.

En cuanto a los encargados de tomar decisiones de PEM durante el sexenio de EPN: ¿tenía alguna importancia ese continente para "forjar ese México en paz, incluyente [...] próspero [...] con responsabilidad global?”, ¿hubo algún cambio en esa percepción que alterara el patrón histórico?, ¿se establecieron criterios para identificar a los principales socios de México en África?, ¿pueden identificarse objetivos, estrategias y acciones concretas en la PEMAf?, ¿se aprecia algún intento de formalización que marque un cambio significativo en esa política?

${ }^{2}$ Este término aparece en un artículo de Guadalupe González, donde explica que el concepto fue elaborado por Samuel Huntington. Guadalupe González González, "Las estrategias de política exterior de México en la era de la globalización”, Foro Internacional, vol. 41, núm. 166 (2001), pp. 624-625.

${ }^{3}$ Pierre Salama, "Las economías emergentes, ¿el hundimiento?”, Foro Internacional, vol. 54, núm. 215 (2014), pp. 8-9. 
En cuanto a la opinión pública mexicana: ${ }^{4}$ ¿Existe una correlación entre la percepción que de África tiene ésta y la de los que toman decisiones en PEM?

Se proponen tres hipótesis:

1. El sexenio estuvo marcado por la incoherencia entre el discurso oficial de PEM y la política interna, en una coyuntura caracterizada por problemas económicos, deterioro de los derechos humanos y corrupción, ${ }^{5}$ y con un jefe de Estado con un bajo nivel de aprobación interna. ${ }^{6}$ En cambio, en el discurso oficial se afirmaba que México era un país con liderazgo internacional, comprometido en la construcción de la nueva arquitectura mundial.

2. Las relaciones con África no están al margen de la problemática que se deriva de la dependencia de México vis-àvis EEUU, la cual constituye la principal condicionante de la PEM. Ante la política proteccionista del régimen de Trump, como medida reactiva encabezada por distintas instancias

${ }^{4}$ Los estudios de la opinión pública en México son recientes y limitados, en especial en el campo de la PEM, aunque en años recientes han tomado fuerza, en particular desde el inicio del proyecto México, las Américas y el Mundo (мAM), del Centro de Estudios e Investigación Económica (CIDE). Un informe de ese proyecto -publicado en 2018- se usó en el presente artículo. Gerardo Maldonado, Karen Marín, Guadalupe González y Jorge A. Schiavon, Los mexicanos ante los retos del mundo: opinión pública, líderes y política exterior 2016-2017, México, CIDE, 2018; Rodrigo Morales Castillo y Jorge A. Schiavon, "El efecto de la opinión pública en la política exterior de México: contrastando las teorías realistas y liberales", Foro Internacional, vol. 55, núm. 221 (2015), pp. 671-674.

${ }^{5}$ En el informe provisional de la tercera revisión del Examen Periódico Universal (EPU) de la situación de los derechos humanos de la ONU, en noviembre de 2018, se destacó que algunas organizaciones ciudadanas afirmaban que entre 2013 y 2018 se registró un "retroceso en los derechos humanos". Centro de Estudios Internacionales (CEI) Gilberto Bosques, Examen Periódico Universal (EPU), como evaluación de la situación de los Derechos Humanos; Recomendaciones para México, México, Senado de la República, 15 de noviembre de 2018, p. 5, CI_EPU_151118.pdf

${ }^{6}$ Ma. Fernanda Somuano, "Aprobar al presidente. Una comparación entre Felipe Calderón y Enrique Peña Nieto”, Foro Internacional, vol. LVIII, núm. 234 (2018), pp. 631-639, 647. 
gubernamentales y en parte para aminorar su impacto negativo, se lanzó una estrategia enfocada en la búsqueda de mercados de inversión y exportación de productos mexicanos en África.

3. A partir de la tesis de Salama respecto a que algunos países antes calificados como "periferia", hoy en día considerados economías emergentes, pueden tender a convertirse en subimperialismos en regiones de menor desarrollo, se aprecia la tendencia del "regreso hacia una estructura de exportaciones que privilegia [...] los productos primarios en detrimento de los productos industriales" (denominada "nueva primarización”), y el temor de que México pretenda convertirse en un país subimperialista en África. ${ }^{7}$

Este artículo esta dividido en tres secciones. En la primera, una breve revisión de las principales transformaciones mundiales -que inciden en México y en los países africanoses el punto de partida para comprender la situación de la PEMAf al inicio de la administración de EPN. Se plantean argumentos para analizar la PEM y que éstos fueron decisivos en los cambios registrados en la PEMAf.

La segunda sección tiene como finalidad documentar las principales acciones de PEMAf en ese sexenio, identificando los rasgos de continuidad y cambio en relación con otros sexenios. En el Plan Nacional de Desarrollo 2013-2018 (PND) se estableció el eje central de la PEM ("México como un país con responsabilidad global"), sin embargo, no se definieron estrategias y acciones que debían ser aplicadas.

En la tercera sección, ante la ausencia de una definición de estrategias y acciones y con la finalidad de identificar el posible impacto de las acciones tomadas, se optó por distinguir algunos criterios que sirvan para evaluar la Pemaf. Se tomó en cuenta la forma en que un sector de la opinión pública mexicana percibía la PEM. Se tomó como base el infor-

${ }^{7}$ Salama, “Las economías emergentes ...", art. cit., pp. 8-9. 
me Los mexicanos ante los retos del mundo: opinión pública, líderes y política exterior 2016-2017.8

En la conclusión se resumen las respuestas a las preguntas de investigación planteadas. Se subraya que, a pesar de que el discurso oficial supondría rupturas en el patrón histórico de la PEMAf, éste en esencia se mantiene en cuanto a la invisibilidad del continente africano en la agenda de la PEM, la debilidad de la estructura y de una diplomacia tradicional de bajo perfil. El principal cambio residió en el giro hacia la política económica exterior (PEE), pero que sería contradictoria.

\section{UN AMBIENTE MUNDIAL INCIERTO Y COMPLEJO}

La aceleración de transformaciones mundiales plantea nuevos retos para México y para los Estados africanos, y genera cambios internos ante el surgimiento de fenómenos inéditos, precipitados por la globalización, ${ }^{9}$ además de que adquirieron relevancia las potencias medias emergentes, con características diferentes de las potencias medias tradicionales. ${ }^{10}$ La globalización está asociada, inter alia, con avances tecnológicos pero también con nuevas presiones (una nueva era de desigualdades) y puede explicarse como un proceso histórico, complejo y "multifacético de interconexión creciente" que comprende la economía, la internacionalización de

${ }^{8}$ En este informe se reproducen las respuestas tanto de población común como de líderes; en este artículo se sintetiza como opinión pública. Maldonado, Marín, González y Schiavon, Los mexicanos ante los retos del mundo..., op. cit.

${ }^{9}$ El tema de globalización esta basado in extenso en González, "Las estrategias de política exterior...", art. cit.; Pierre-Noël Giraud, "Comment la globalisation façonne le monde”, Politique Étrangère, vol. 71, núm. 4 (2006); Salama, "Las economías emergentes...", art. cit.

${ }^{10}$ Günther Maihold y Zirahuén Villamar, "El G20 y los países emergentes”, Foro Internacional, vol. 56, núm. 223 (2016), p. 169. 
la política y "el surgimiento de redes sociales de carácter transnacional". 11

Con la globalización se incrementó la relevancia de las instituciones internacionales y surgió, en palabras de Salama, un "desequilibrio del centro de gravedad del mundo", provocado por algunos países asiáticos, sobre todo China. Esto implica una "estructura híbrida del poder internacional", 12 compuesta por un sistema unipolar, con una superpotencia político-militar, y por un sistema multipolar en lo económico, en el que coexisten viejos y nuevos poderes, con la aparición de las potencias medias emergentes. De acuerdo con Giraud, los emergentes podrán incorporarse en la globalización, pero otros países -gran parte de los africanos- se estancarán o retrocederán. Algunas de estas potencias han intentado formar instituciones internacionales, a veces con un buen nivel de organización, como los BRICs (Brasil, Rusia, India, China y Sudáfrica), pero otras parecen haber sido efímeras, como los mint (con cuatro integrantes, incluidos México y Nigeria). ${ }^{13}$

En un fenómeno que suele denominarse "pertenencias múltiples" y que fue utilizado en el discurso oficial de PEM de la administración de Felipe Calderón Hinojosa (FCH) y de EPN, los países emergentes buscan tener presencia en distintos espacios de política internacional. Algunos mercados, que tenían mayores posibilidades, podrían convertirse en "locomotoras del crecimiento económico a nivel mundial". ${ }^{14} \mathrm{La}$ participación de países africanos en esos esquemas de eco-

${ }^{11}$ González, art. cit., p. 619.

${ }^{12}$ El planteamiento de la creciente relevancia de las instituciones internacionales en "número, alcance y poder" corresponde a González, ibid, pp. 624-625.

${ }^{13}$ Maihold y Villamar atribuyen el término de "países emergentes" a agencias internacionales de calificación de riesgos, como Goldman Sachs, que intentaban promover sus recursos financieros en los nuevos mercados. Maihold y Villamar, "El G20 y los países emergentes", art. cit., pp. 165-166.

14 Ibid, pp. 167-168. 
nomías emergentes es débil: aunque son 55, sólo figuran unos seis o siete.

$\mathrm{Al}$ inicio de la década de 2010, Salama, al observar dos grandes problemas que enfrentaba México (bajo crecimiento económico y excesiva dependencia frente a EEUU), planteó que la economía emergente mexicana podía encontrarse "al final de un ciclo de expansión iniciado en los años 2000 y que podría manifestarse mediante el regreso del [...] «crecimiento-hundimiento», que las caracterizó en el pasado". Hay grandes diferencias entre las economías de los países emergentes. En el caso de China, un rasgo distintivo es que exporta sobre todo productos manufacturados. Hay países que eran parte de la "periferia”, pero al adquirir condiciones que correspondían al "centro", tienden a comportarse como subimperialismos hacia países de menor desarrollo.

En México, la producción de las maquiladoras se destinaba básicamente a Eeuu y Canadá en el marco del Tratado de Libre Comercio (TLC). Desde el inicio del siglo, las exportaciones mexicanas dejaron de estar basadas en artículos industriales para concentrarse en productos primarios, fenómeno que Salama denomina la nueva "primarización" de la economía, que implica su desindustrialización. ${ }^{15}$ Para el Estado, esas exportaciones significan el ingreso de impuestos. A esto se suma la dependencia de México vis-à-vis las remesas de los trabajadores mexicanos en EeuU.

Salama advierte que los criterios para medir la pobreza y la clase media difieren entre países industrializados y emergentes y, por lo, tanto son términos imprecisos. Sin embargo, suele afirmarse que en los países emergentes -incluidos los africanos- tiende a crecer la clase media con poder adquisitivo.

${ }^{15}$ Salama, "Las economías emergentes...", art. cit., pp. 17-18. 


\section{África en la globalización}

Es incuestionable el involucramiento de México en el proceso de globalización. ${ }^{16} \mathrm{El}$ análisis del continente africano en ésta es complejo y contradictorio. África se distingue por su pluralidad y diversidad histórica, sociopolítica, religiosa, económica, lingüística y geográfica. Con una población superior a los 1282 millones de habitantes (2018), esta integrada por 55 Estados. ${ }^{17}$

Suponer que África está al margen de la globalización denota desconocimiento de la posición del continente en la "estructura híbrida del poder internacional". Samir Amin ${ }^{18}$ sostiene que en la práctica -debido al bajo nivel de desarrollo económico y tecnológico de la mayoría de esos países-África es, en forma simultánea, una de las regiones más integradas y la más pobre en la globalización. Sus países no escapan al severo impacto de fenómenos y tendencias del proceso de globalización y del surgimiento de la "estructura híbrida del poder internacional".

Desde el inicio del siglo xxi, la mayoría de esos países registran transformaciones políticas, económicas y sociales que se expresan en programas de apertura económica neoliberal, en esfuerzos de integración subregionales y en intentos en favor de la gobernabilidad democrática. Al igual que en México, en África por lo general esos programas han sido de "carácter reactivo, desigual, parcial y en ocasio-

16 Guadalupe González la define como una "globalización incompleta” debido a que se realizó, entre otras condiciones, en un proceso de liberación económica desigual y en medio de una crisis de legitimidad del régimen político. González, art. cit., pp. 620-622.

17 En la República Árabe Saharaui Democrática, RASD, desde que el colonialismo español abandonó ese territorio (1976), Marruecos inició un proceso de ocupación que se mantiene hasta la fecha. A pesar de que la Corte Internacional de Justicia declaró ilegal esa ocupación, hay Estados que no reconocen a la RASD. México figura entre los que sí la reconocen.

18 Samir Amin, “África: living on the fringe?”, Africa Insight, 2001, vol. 31, núm. 2, p. 3 
nes contradictorios", ${ }^{19}$ en cuyo contexto se concretan -o se inhiben- las formas de inserción en la nueva dinámica global. Uno de los retos es el acceso a los avances tecnológicos producidos en países occidentales.

Son pocos los países africanos considerados potencias emergentes involucradas -con sus contradicciones- en el proceso de globalización. Sin embargo, hay datos que suelen desdeñarse: el crecimiento económico de la región subsahariana en 2018 fue de $3.1 \%$ y se acelerará entre 2019-2020; las exportaciones de la región subsahariana registraron una tasa de crecimiento anual de $32.3 \%$ (no hay datos para el norte de África); de los 52 países africanos de los que se tienen datos (2017), 11 registran ingresos medios altos (como México) y 15 ingresos medios bajos. La mayoría de sus exportaciones son materias primas esenciales para las economías de los países industrializados, en especial los europeos, algunos asiáticos -como China-, Rusia, EEuU y Canadá. Los países africanos son una parte fundamental de la globalización sin la cual la economía internacional no podría subsistir. ${ }^{20}$

Al principio de la administración de EPN, la percepción era que África -con algunas excepciones- era "irrelevante" en la nueva dinámica mundial y para México.

\section{La (nueva) agenda de politica exterior}

$\mathrm{Al}$ inicio del sexenio de Felipe Calderón Hinojosa (FCH), en el discurso oficial destacaba la idea de México como un país con pertenencias múltiples y protagonista en la construcción del orden mundial. Pero en la práctica era un discurso sin contenido, ya que al principio del sexenio la PEM no era una

${ }^{19}$ Estos términos son usados por González para explicar la decisión de la elite política mexicana de fomentar el proceso de globalización. González, art. cit., p. 621.

${ }^{20}$ Africa Developments Indicators 2012-2013, p. 68; World Development Indicators 2017, Washington, World Bank Group, 2017, pp. VI-VII. 
prioridad de política pública ${ }^{21}$ y en sus primeros años de gobierno se mantuvo un bajo perfil a nivel mundial, con una posición pragmática cercana a EEUU, compromisos selectivos con instituciones internacionales y un crecimiento económico vinculado con el comercio exterior y las IED. ${ }^{22}$ Debido a presiones internas y externas, la PEM adquirió una nueva relevancia, con un fuerte impacto negativo en la imagen internacional de México, al quedar vinculada con la "seguritización" del país debido al aumento de la violencia interna, aunada a la corrupción y al mal manejo de la economía, ${ }^{23}$ lo que generó criticas de EEUU.

Para tratar de construir una imagen positiva, al inicio del gobierno de EPN se intentó eliminar la imagen de inseguridad interna y corrupción, proponiendo un nuevo discurso de PEM centrado en reformas estructurales, la promoción de oportunidades económicas y proyectando un país con liderazgo internacional. Uno de los objetivos era evitar que México quedara excluido de los mercados internacionales. ${ }^{24}$ Fue un intento efímero. África seguía siendo un continente ausente.

A corto plazo, la situación interna empañó el papel de México como líder internacional y la "seguritización" tomó nueva fuerza, pasando a un segundo plano las reformas estructurales. A partir de enero de 2017, en el marco de la nueva política proteccionista de la administración Trump, la relación

${ }^{21}$ Rafael Velázquez Flores y Roberto Domínguez, "El balance de la política exterior de México en el sexenio de Felipe Calderón: límites y alcances” en Humberto Garza Elizondo, Jorge A. Schiavon, Rafael Velázquez Flores (eds.), Balance y Perspectivas de la Política Exterior de México 2006-2012, México, El Colegio de México-CIDE, 2014, p. 51.

${ }^{22}$ González explica las condiciones en las cuales inició la incorporación de México en la globalización y los cambios en la elite política que incidieron en la PEM. González, art. cit., pp. 620-624, 629-630.

${ }^{23}$ Jorge Chabat, "La seguridad en la política exterior de Calderón", en Humberto Garza Elizondo, Jorge A. Schiavon, Rafael Velázquez Flores (eds.), Balance y perspectivas de la política exterior de México 2006-2012, México, El Colegio de México-CIDE, 2014, pp. 318, 632, 639, 643; Somuano, "Aprobar al presidente...", art. cit., pp. 632, 639, 643.

${ }^{24}$ González, art. cit., p. 626. 
con EEUU se volvió tensa y se ahondó el carácter conflictivo de la migración mexicana indocumentada y del narcotráfico. Se generó una fractura entre el discurso oficial de la PEM -que proyectaba la imagen de un país con responsabilidad internacional y se enfatizaba "México como un país estable y atractivo para las IED"- y la difícil realidad de México y un gobierno que enfrentaba un alto nivel de desaprobación de la opinión pública. ${ }^{25}$

El estimulo de la globalización se tradujo en cambios importantes en la agenda internacional, que asumió un tono pragmático, con la relevancia de temas económicos, con la búsqueda de tratados de libre comercio y opciones estratégicas limitadas para enfrentar la hegemonía de EEUU. ${ }^{26}$ La PEM quedó volcada en los asuntos vinculados con EEUU. Con una diplomacia de bajo perfil e, incluso, ambivalente, el proceso de toma de decisiones de política exterior -antes centralizado- se volvió fragmentado y disperso, con la creciente participación de los secretarios de Comercio y de Hacienda en las decisiones vinculadas con la PEE. ${ }^{27}$

\section{El giro HACIA LA POLÍTICA ECONÓMICA}

Schiavon y Figueroa destacan algunos de los principales indicadores para analizar las capacidades institucionales de la SRE en la conducción de la PEM, de los cuales tres pueden ser aplicables en este estudio: los poderes legales (centralización de facultades), la infraestructura diplomática (número y tamaño de representaciones en el exterior) y los recursos humanos (personal y su profesionalización). ${ }^{28}$

25 Somuano, art. cit., pp. 634, 642.

26 González, art. cit., pp. 626-627, 629, 630-631, 634.

27 Ibid, pp. 639-640.

28 Para el otro indicador no se encontró información (PEMAf) : los recursos financieros (presupuesto y su distribución). Los autores aportan una conclusión que puede aplicarse al caso de África: "un presupuesto insuficiente y a la baja", Jorge A. Schiavon y Bruno Figueroa, "Las capaci- 
En el sexenio de EPN hubo tres cambios en la dirección de la SRE: José Antonio Meade, Claudia Ruiz Massieu y Luis Videgaray ${ }^{29}$ En todo el sexenio, Carlos Alberto de Icaza estuvo al frente de la Subsecretaría de Relaciones Exteriores, bajo cuya responsabilidad estaban el Instituto Matías Romero y las relaciones bilaterales con los países de Europa, Asia-Pacífico, África y Medio Oriente, o sea entre 169 (al principio del sexenio) y 170 (al final del sexenio), además de varias organizaciones regionales, como la Unidad Africana (UA). En esa Subsecretaría, África y Medio Oriente están integradas en una misma Dirección General (DGAMO), lo que implica que muchas veces los datos de las dos regiones aparecen como si fueran una unidad, sin distinguir qué acciones correspondían a África. Frente a la relevancia geoestratégica del Medio Oriente-que incluye a Israel-, África parecía perder día a día importancia, reduciéndose su escasa visibilidad.

Aunque hubo diferencias, derivadas de la personalidad del jefe de la cancillería, el verdadero giro -con énfasis en temas económicos- fue generado por los cambios en la realidad tanto interna como internacional. En cuanto al Senado de la República, en la LXIV Legislatura, la Comisión de Relaciones Exteriores África fue ampliada para incluir a Asia-Pacífico, región para la cual la PEM era notablemente más activa.

La infraestructura de PEMAf era débil ${ }^{30}$ y su presupuesto financiero, limitado, hechos no acordes con el discurso oficial de México como país con responsabilidad global. En ese

dades de la política exterior de México: diagnóstico (2000-2018) y propuestas (2018-2024)", en Jorge A. Schiavon, Rafael Velázquez Flores y Humberto Garza (eds.), La política exterior de México 2018-2024: diagnóstico y propuestas, México, CIDE-Universidad Autónoma de Baja California-Universidad Autónoma de Nuevo León, 2018, pp. 17-19.

${ }^{29}$ En este apartado han sido usados in extenso los Informes de labores de la SRE, comunicados de prensa de la misma Secretaría y distintos documentos, informes y comunicados del Senado de la República. Se reportan principalmente datos numéricos.

${ }^{30}$ En cuanto a la red diplomática y consular, se le consideraba "concentrada y limitada”, Schiavon y Figueroa, art. cit., p. 19. 
continente había sólo ocho embajadas mexicanas ${ }^{31}$ y, en general, contaban con tres o cuatro funcionarios diplomáticos, más uno o dos administrativos. Todos los embajadores mexicanos tienen acreditaciones múltiples, en países no siempre cercanos geográficamente y muy diferentes entre sí.

México es el país que cuenta con la mayor cantidad de consulados en EEUU, pero en África sólo había 14. Son consulados honorarios, dirigidos por personas relevantes en el ámbito local, casi siempre empresarios con nexos estrechos con su gobierno, con lazos económicos con México y sin vínculos con la política interna de México. Hay muy pocos mexicanos residentes en África. En el extremo sur del continente (12 países), la comunidad mexicana sumaba 420 personas a inicios de 2018. ${ }^{32}$ Muchas veces son residentes temporales (empresarios o estudiantes) y es probable que no todos los mexicanos que viven en África estén registrados.

\section{La diplomacia tradicional}

Los países aliados de México siguieron siendo los mismos que en el sexenio anterior. Sólo se sumó Ghana, con la apertura de una embajada, pero los trámites correspondientes comenzaron en el sexenio de FCH. Calificados en documentos oficiales como países con las economías más dinámicas del continente, sin embargo, no hay criterios claros que permitan saber por qué se les definió como aliados: Angola, Argelia, Côte d'Ivoire, Egipto, Etiopía, Ghana, Kenia, Marruecos, Nigeria y Sudáfrica. En su mayoría, estos países son potencias medias emergentes, aunque algunos son frágiles, debido a problemas con la oposición, a conflictos internos y dificultades económicas. Entre las tendencias positivas destacan nue-

${ }^{31}$ Argelia, Egipto, Etiopía, Kenia, Marruecos, Nigeria, Sudáfrica y Ghana, abiertas en este sexenio.

32 "Embajada de México en Sudáfrica, Secretaría de Relaciones Exteriores, sitio de internet, htpps://embamex.sre.gob.mx->Sudafrica 
vos jefes de Estado -que auguran mayor apertura política y mejoría de los derechos humanos- en Angola, Sudáfrica y Etiopía y, en general, un gran dinamismo sociopolítico con clases medias en ascenso.

En fuentes mexicanas casi siempre se hace referencia a la corrupción en África pero, en 2017, de acuerdo con el Índice de Percepción de la Corrupción (IPC), siete de esos diez aliados registraron un IPC menor que el de México y sólo tres (Kenia, Nigeria y Angola) resultaron ser más corruptos que nuestro país. ${ }^{33}$

A pesar de que en el $6^{\circ}$ Informe de Gobierno se subrayó la relevancia para México de la intensa actividad presidencial en el exterior, con 77 giras, y la visita oficial de 65 jefes de Estado y de gobierno, no hubo ninguna visita oficial de EPN a África ni se entrevistó con un jefe de Estado o de gobierno africano. Un hecho poco publicitado fue su visita no oficial a dos países africanos (en diciembre de 2013): a Sudáfrica, para asistir al funeral del expresidente Nelson Mandela, pero su presencia pasó inadvertida. EPN se entrevistó con el Premio Nobel de Paz sudafricano, Desmond Tutu (y con funcionarios de países no africanos). En ese viaje pasó por Côte d'Ivoire y recibió la visita de cortesía del ministro de Energía de ese país. ${ }^{34}$ Por su parte, en ese viaje, el canciller mexicano se reunió con sus homólogos de Angola y Nigeria.

Casi siempre presentadas en el marco del "diálogo político", hubo numerosas delegaciones que visitaron México, procedentes de más de veinte países africanos. Dos cancilleres mexicanos fueron a África, pero no se trató de visitas oficiales. El primer caso se trató de Meade (ver PEE) y la segunda fue de Ruiz Massieu, quien viajó a Egipto para apoyar a un grupo de connacionales afectado por un acto de terrorismo.

33 "IPC 2017, Transparencia Internacional (sitio de internet), https:// transparencia.org.es/ipc-2017/

${ }_{34}$ Gobierno de la República, Segundo Informe de Labores, 2013-2014, pp. 63,87 . 


\section{Política económica exterior}

El intento de apertura hacia los mercados africanos y el énfasis en la PEE fue el cambio más relevante de la PEMAf. Comenzó cuando Meade era canciller y encabezó a un grupo de hombres de negocios mexicanos, en un viaje de promoción comercial, a Angola, Sudáfrica y Argelia. En este último país se entrevistó con el presidente: fue la única entrevista entre un alto funcionario mexicano y un jefe de Estado africano en ese sexenio.

Fue en los últimos años del sexenio cuando la PEE se convirtió en el sector más dinámico de la PEMAf. Se tomaron medidas importantes para promover las exportaciones e inversiones mexicanas, como la apertura de la primera oficina de ProMéxico en África, ${ }^{35}$ en Marruecos en $2018 .{ }^{36}$ Se destaca la naturaleza de las exportaciones. Algunas fueron productos con componentes industriales, pero en ocasiones se trataba de artículos fabricados por compañías extranjeras, maquilados en México y, en otros casos, eran resultado del comercio triangular (con EEUU). Los casos más notables son Grupo Modelo (empresa belga) y Ruhrpumpen (alemana). Aunque también exportan otras compañías, como Grupo Bimbo, Rotoplas, Cemex, SuKarne y Gruma (harina de maíz y tortillas); el mayor flujo comercial y con mejores posibilidades de crecimiento era el de las materias primas (maíz, garbanzo, aceite, azúcar, carne de pollo, vísceras): la primarización de la economía. La transmisión de tecnología se centra en la nixtamalización.

Las declaraciones de empresarios y funcionarios gubernamentales podían ser contradictorias y exageradas. ${ }^{37}$ Se ha-

${ }^{35}$ En algunas fuentes se afirma que esa apertura estuvo precedida por tres años de esfuerzos.

36 "Visita de trabajo del Subsecretario de Relaciones Exteriores, Embajador Carlos de Icaza, al Reino de Marruecos”, Comunicado núm. 034, Secretaría de Relaciones Exteriores, 27 de febrero de 2018.

37 Véase Ana Gabriela Jiménez, “Así es como México multiplicó por 20 su comercio con África”, El Economista América, 3 de agosto de 2017; 
cía referencia a "un auge extraordinario" de las relaciones comerciales con África. En una noticia se afirmaba que los productores mexicanos "apenas inician sus exportaciones a Asia”, mientras que los africanos eran "mercados ignorados" (lo que contradice el supuesto auge con ese continente) y que se habían identificado 12 países "sin conflictos bélicos". Aunque la lista incluye algunas de las economías africanas con mayor dinamismo, se aprecia que cinco de esos países enfrentan conflictos internos importantes y tres registran un IPC más alto que el de México. ${ }^{38}$ Las cifras del comercio eran insignificantes, la balanza de pagos era deficitaria para México (con excepción de Nigeria) y las exportaciones presentaban una tendencia decreciente. ${ }^{39}$

En el $6^{\circ}$ Informe de Gobierno, EPN afirmó "que México fortaleció los acuerdos económicos y comerciales con África a fin de establecer una relación constructiva y permanente", sin que pueda comprobarse con hechos esta declaración.

\section{Foros multilaterales}

México es observador en foros en los cuales hay una presencia activa de países africanos, como el G20, los BRICS y en la

Gerardo Villafranco, “África: La primera frontera para las empresas mexicanas", ForbesMéxico, 9 de junio de 2017; Fernanada Celis, "Grupo Modelo llevará a Corona hasta Oceanía y África”, ForbesMéxico, 3 de marzo de 2017; "Impulsan comercio México-África", Logística, 27 de octubre de 2017. Nótese que el texto de algunas notas es muy similar, probablemente extraídos de los comunicados de prensa.

${ }^{38}$ Los países son: Angola, Argelia, Botswana, Côte d'Ivoire, Egipto, Etiopía, Ghana, Kenia, Nigeria, Sudáfrica y Tanzania; "Ven a África y Medio Oriente como mercados potenciales para México", Logística, 21 de marzo de 2017.

${ }^{39}$ En 2017, Egipto fue el socio comercial número 67 de México a nivel mundial y el quinto entre los países africanos. Ese año, el comercio fue inferior al de 2016 y, en ese mismo periodo, las exportaciones mexicanas disminuyeron $26 \%$. El comercio con los principales socios africanos representa para México porcentajes muy bajos: Sudáfrica, 0.07\%; Marruecos, $0.3 \%$, Argelia, $0.02 \%$. 
Organización Internacional de la Francofonía. En algunas organizaciones africanas, México participó como observador: en la UA y en la Comunidad de Estados de África Occidental (conocido por sus siglas en inglés como EcowAs).

México participó en distintos espacios de la onU vinculados con temas africanos, como el Grupo de Contacto sobre Piratería en las costas de Somalia y el Consejo de los Derechos Humanos. Tuvo presencia en varias iniciativas de ayuda humanitaria a África en el marco de la onU, como el Proyecto de Respuesta Rápida de Emergencia del programa Mundial de Alimentos y el Fondo Internacional de Emergencia de las Naciones Unidas para la Infancia. En la Comisión de Desarrollo Social de la onu se creó la Alianza para el Desarrollo de África, con la participación de México, que hizo una aportación financiera vía la Organización Mundial de la Salud (oms) para apoyar a Guinea, Liberia y Sierra Leona, afectados por la epidemia de ébola.

En la ONU, la participación mas relevante de México es en las Operaciones de Mantenimiento de Paz, omp. Desde 2015, personal de la Secretaría de la Defensa Nacional y de la Comisión Nacional de Seguridad forma parte de las OMP, si bien en términos numéricos es simbólica, a veces sólo con observadores militares. A finales de 2018 había un pequeño número en la RASD y en dos de los conflictos africanos más riesgosos, en la República Centroafricana y en Mali.

México no se integró como miembro en ninguna institución internacional de reciente formación. En la época del primer canciller, adquirió cierta relevancia el grupo denominado mint (México, Indonesia, Nigeria y Turquía). Aunque se afirmaba que sería "el siguiente gigante económico”, en los últimos años del sexenio prácticamente desapareció. ${ }^{40}$

${ }^{40}$ Jim O'Neill, “The MINT countries: Next economic giants?”, $B B C$ News, 6 de enero de 2014. 
La parte más débil siguió siendo la formalización de esfuerzos comunes, con impacto positivo en México y en África. Como en sexenios pasados, fueron firmados memorandos de entendimiento con varios países, pero no hay datos que permitan comprobar sus resultados. Se firmaron convenios de cooperación educativa-cultural y hay datos que implican que pudieron participar 21 países africanos en este tipo de acuerdos, pero no se especifica cuáles.

Entre los esfuerzos de institucionalización destacan el Tratado sobre Extradición México-Sudáfrica, el Tratado sobre Asistencia Jurídica Mutua en Materia Penal México-Sudáfrica y el Acuerdo de Cooperación Turística México-Sudáfrica, y la creación de la Cámara de Comercio Nigeriana-Mexicana. Con este último país, se firmaron tres instrumentos para promover las inversiones y el intercambio comercial.

\section{EL IMPACTO DE LAS ACCIONES EMPRENDIDAS}

El PND estableció cuatro objetivos vinculados con el eje "México con responsabilidad global" y cada uno tenía metas específicas:

Ampliar y fortalecer la presencia de México en el mundo; promover el valor de México en el mundo mediante la difusión económica, turística y cultural; reafirmar el compromiso del país con el libre comercio, la movilidad de capitales y la integración productiva; y velar por los intereses de los mexicanos en el extranjero y proteger los derechos de los extranjeros dentro del territorio nacional.

Eran lineamientos generales e imprecisos. En las tres metas no hay documentos que prueben que se cumplieron mediante la PEMAf. La presencia diplomática de México en África se mantuvo, grosso modo, en los mismos niveles que durante la 
administración de FCH. Es indudable que aumentó el atractivo de México en África, pero no como resultado de acciones mexicanas, sino por el interés de esos países en aproximarse al nuestro porque era miembro del TLC, lo que podría implicar mejores condiciones para el ingreso a los mercados de Canadá y de EEUU. Los países africanos esperaban obtener de México acuerdos amplios de cooperación, atraer inversiones de capital mexicano y, sobre todo, intentar acercarse a los mercados de Norteamérica.

En la reafirmación del libre comercio, a pesar de que México es el país con la mayor cantidad de acuerdos de libre comercio en el mundo, no existe ninguno con países africanos. La tercera meta puede tener una respuesta afirmativa si se toman en cuenta los comunicados de prensa de la SRE y el número reducido de mexicanos residentes en países africanos.

Para evaluar la PEMAf es fundamental precisar criterios de análisis. En documentos oficiales no se encontró ningún diagnóstico del continente que sirviera para definir prioridades, objetivos y acciones concretas, no hay criterios claros para determinar a ciertos Estados como aliados estratégicos. En este estudio se optó por tomar como base las respuestas dadas por la opinión pública en torno a la PEM y presentados en la publicación Los mexicanos ante los retos del mundo: opinión pública, líderes y política exterior, ${ }^{41}$ por ser representativa de la forma en la cual la opinión publica mexicana percibe a África: sólo hay tres pequeñas menciones al continente, lo que permite comprobar la ausencia de África en documentos vinculados con la PEM, en un nexo estrecho con los medios. Como explica Somuano, como resultado de diferentes investigaciones, puede sostenerse que las actitudes de la gente que responde encuestas reflejan las ideas que tienen en ese momento:

${ }^{41}$ Maldonado, Marín, González y Schiavon, Los mexicanos ante los retos del mundo..., op. cit. 
Las cargas cognitivas de los individuos para poder emitir juicios o tomar decisiones no se basan en información comprehensiva e integrada, es decir que el público [...] toma atajos cognitivos basados en los temas que los medios posicionan. La familiaridad que los individuos tienen con temas políticos [está relacionada] con la cantidad y tiempo que esos asuntos reciben de los medios masivos. ${ }^{42}$

Para los fines de este estudio, destacan las respuestas de la opinión pública: el racismo -vinculado con el color de la piel-que permea nuestra sociedad, que afecta directamente a mexicanos comunes, así como qué instrumentos de política exterior debían privilegiarse.

La opinión publica demostró nulo interés por África. De la política publica, el sector mejor calificado fue el de la PEM. A la pregunta de qué instrumentos debían ser usados para fortalecer la posición internacional de México, los entrevistados se pronunciaron en favor de la "diplomacia blanda", principal instrumento utilizado en la PEMAf. En una conclusión preliminar, uniendo el desinterés de la opinión pública por África, el racismo profundo en nuestra sociedad y el alto nivel de aprobación de la PEM -con la influencia ejercida por los medios- en general, puede afirmarse que la PEMAf sería respaldada a nivel interno. Esta conclusión es inversa a los intereses de quienes defendemos la tesis de que, aunque África nunca ha sido una prioridad en la PEM, su ausencia no implica que sea irrelevante, al contrario. No puede pensarse en un mundo globalizado que excluya a África.

Un punto importante es que ha crecido ligeramente el porcentaje de la opinión pública contraria a la participación en las omp, o que afirma que en todo caso deberían ser desplegadas en Centroamérica y en el Caribe. Entre los temas que la opinión pública mexicana considera que afectan menos la situación tanto personal como la de México destacan los conflictos internacionales (lo que involucra a África).

${ }^{42}$ Somuano, “Aprobar al presidente...", art. cit., pp. 640-641. 
Ante el gran crecimiento de migrantes africanos no documentados, concentrados en Tijuana y en otras ciudades fronterizas, ese tema podría adquirir relevancia para la política interna.

\section{Conclusión}

Entre los principales hallazgos de este estudio están el gran desinterés y desconocimiento de África, tanto entre la opinión pública como entre los distintos sectores que inciden en la toma de decisiones vinculadas con la PEM, incluida la económica, con su casi total ausencia en los medios y en la agenda de la PEM. De esto se deduce que carecía de importancia dicho continente para "forjar ese México $[. .$.$] con responsa-$ bilidad global". Como parte de la conclusión, se mantiene la vigencia de la hipótesis de la tendencia a convertirse en exportador de materias primas, con el temor de que se pretenda imitar el comportamiento de subimperialismo en África.

El principal cambio en la percepción de África reside en su potencial económico, como mercado de exportaciones y de inversiones. Pero persiste el imaginario occidental y el desconocimiento. A pesar de un relativo activismo económico, en el sexenio de EPN se deterioró la posición de África en la PEM.

\section{BibLiogRAFÍA}

Africa Development Indicators 2012-2013, Washington, The World Bank, 2013.

Celis, Fernanda, "Grupo Modelo llevará a Corona hasta Oceanía y África”, Forbes México, 3 de marzo de 2017.

Снават, Jorge, "La seguridad en la política exterior de Calderón", en Humberto Garza Elizondo, Jorge A. Schiavon, Rafael Velázquez Flores (eds.), Balance y perspectivas de la política exterior de 
México 2006-2012, México, El Colegio de México-CIDE, 2014, pp. 317-341.

Examen Periódico Universal (EPU), como evaluación de la situación de los Derechos Humanos; Recomendaciones para México (CI_EPU_15118. pdf), México, Centro de Estudios Internacionales (CEI) Gilberto Bosques, Senado de la República, 15 de noviembre de 2018. Giraud, Pierre-Noël, "Comment la globalisation façonne le monde”, Politique Étrangère, vol. 71, núm. 4 (2006), pp. 927-940.

González González, Guadalupe, "Las estrategias de política exterior de México en la era de la globalización”, Foro Internacional, vol. 41, núm. 166 (2001), pp. 619-671.

"Impulsan comercio México-África”, Logística, 27 de octubre de 2017.

"IPC 2017, Transparencia Internacional (sitio de internet), https:/ / transparencia.org.es/ipc-2017

Jiménez, Ana Gabriela, "Así es como México multiplicó por 20 su comercio con África”, Economía hoy, 3 de agosto de 2017.

Maihold, Günther y Zirahuén Villamar, "El G20 y los países emergentes”, Foro Internacional, vol. 56, núm. 223 (2016), pp. 165-211.

Maldonado, Gerardo, Karen Marín, Guadalupe GonZÁlez y Jorge A. Schiavon, Los mexicanos ante los retos del mundo: opinión pública, líderes y política exterior, 2016-2017, México, CIDE, 2018.

O'Neill, Jim, "The Mint countries: Next economic giants?”, $B B C$ News, 6 de enero de 2014.

Salama, Pierre, "Las economías emergentes, ¿el hundimiento?", Foro Internacional, traducción de Ana Inés Fernández Ayala, vol. 54, núm. 215 (2014), pp. 5-30.

Secretaría de Comunicaciones y Transportes, "La marca México está hecha de logros", México, sct, 13 de noviembre de 2018, https://www.gob.mx/sct/articulos/la-marca-mexico-esta-he cha-de-logro

Schiavon, Jorge A. y Bruno Figueroa, "Las capacidades de la política exterior de México: diagnóstico (2000-2018) y propuestas (2018-1024)", en Jorge A. Schiavon, Rafael Velázquez Flores y Humberto Garza (eds.), La política exterior de México 2018-2024: Diagnóstico y propuestas, México, CIDE-Universidad Autónoma de 
Baja California-Universidad Autónoma de Nuevo León, 2018, pp. 17-24.

Senado de la República, Comisión Asia-Pacífico-África de la LXIV Legislatura, Primer Año de Ejercicio 2018.

Somuano, Ma. Fernanda, "Aprobar al presidente. Una comparación entre Felipe Calderón y Enrique Peña Nieto", Foro Internacional, vol. LVIII, no. 234 (2018), pp. 629-670.

Velázouez Flores, Rafael y Roberto Domínguez, "El balance de la política exterior de México en el sexenio de Felipe Calderón: límites y alcances”, en Humberto Garza Elizondo, Jorge A. Schiavon, Rafael Velázquez Flores (eds.), Balance y Perspectivas de la Política Exterior de México 2006-2012, México, El Colegio de México-CIDE, 2014, pp. 51-83.

"Ven a África y Medio Oriente como mercados potenciales para México", Logística, 21 de marzo de 2017.

Villafranco, Gerardo, "África: La primera frontera para las empresas mexicanas”, Forbes México, 9 de junio de 2017.

World Development Indicators 2017, Washington, World Bank Group, 2017, https://openknowledge.worldbank.org/hand le/10986/26447

\section{INFORMES, LEYES E INSTRUMENTOS INTERNACIONALES}

Secretaría de Relaciones Exteriores, Informe de Labores, 2012-2013, México, SRE.

Secretaría de Relaciones Exteriores, Informe de Labores, 2013-2014, México, SRE.

Secretaría de Relaciones Exteriores, Informe de Labores, 2014-2015, México, SRE.

Secretaría de Relaciones Exteriores, Informe de Labores, 2015-2016, México, SRE.

Secretaría de Relaciones Exteriores, Informe de Labores, 2016-2017, México, SRE.

Secretaría de Relaciones Exteriores, Informe de Labores, 2017-2018, México, SRE. 
